\title{
Estudo histológico comparativo de implantes (ímãs) em órbitas de coelhas
}

\author{
Comparative histologic study of implants(magnets) in orbits offemale rabbits
}

Elcio Roque Kleinpaul ${ }^{1}$

Harley Edison Amaral Bicas ${ }^{2}$

\footnotetext{
${ }^{1}$ Doutor pela Faculdade de Medicina de Ribeirão Preto da Universidade de São Paulo. Ribeirão Preto (SP).

${ }^{2}$ Professor Titular do Departamento de Oftalmologia, Otorrinolaringologia, Cabeça e Pescoço da Faculdade de Medicina de Ribeirão Preto da Universidade de São Paulo. Ribeirão Preto (SP).

Endereço para correspondência: Av. Presidente Wilson, 1202 - Apto. 2 - São Vicente (SP) CEP 11320-000 E-mail: elcioroq@ig.com.br

Recebido para publicação em 07.05.2004

Versão recebida em 15.03.2005

Aprovação em 24.05.2005
}

\begin{tabular}{|l|}
\hline RESUMO \\
\hline Objetivos: Avaliação microscópica dos sinais da reação inflamatória \\
causada pela fixação de implante orbitário (ímã, recoberto por ouro). \\
Métodos: Estudo experimental em 54 coelhas adultas, divididas em três \\
grupos de 18, com 3 subgrupos de 6, avaliação com uma, três e seis semanas \\
de pós-operatório. Fixação, no rebordo inferior da órbita, de implante (ímã \\
e ouro) por meio de cola, parafuso ou fio inabsorvível (Mersilene 5.0 $0^{\circledR}$ ). As \\
órbitas contralaterais (sem implante) compuseram o grupo-controle. Resul- \\
tados: Sinais histológicos de reação inflamatória à fixação orbitária do \\
implante foram observados, com cianoacrilato, parafuso, ou sutura inab- \\
sorvível(Mersilene 5.0 ${ }^{\circledR}$ ), até a sexta semana pós-operatória, com predomí- \\
nio do processo inflamatório crônico e fibrótico cicatricial, sem demonstrar \\
diferenças estatisticamente significativas na maior parte dos casos. Conclu- \\
são: O exame histopatológico demonstrou, na maior parte das órbitas com \\
e sem implante, presença de reação inflamatória aguda e crônica até a sexta \\
semana pós-operatória, com predomínio de processo inflamatório crônico \\
e fibrótico cicatricial, sem demonstrar, na maior parte dos casos, diferenças \\
estatisticamente significante entre os grupos experimental e controle. \\
\hline
\end{tabular}

Descritores: Implantes orbitários/efeitos adversos; Magnetismo/uso terapêutico; Ouro/ efeitos adversos; Nistagmo patológico/cirurgia; Coelhos; Estudo comparativo

\section{INTRODUÇÃO}

Apesar dos avanços na área da motricidade ocular, há uma lacuna importante no que diz respeito à geração de forças binoculares combinadas, para restauração das perdas de ação muscular ou para o bloqueio de vários tipos de nistagmo, nos quais a correção cirúrgica não atinge os objetivos propostos.

Estudos têm sido realizados para se tentar substituir as forças musculares, utilizando-se métodos de contato material direto ou indireto. O contato material direto (músculos ou fios elásticos presos à esclera) oferece algumas desvantagens: os vínculos entre o material e o olho sofrem interferências mecânicas de tecidos vivos, como neoformações cicatriciais.

Uma alternativa é o possível aproveitamento de campos magnéticos (sem contato material direto, entre o elemento gerador de força e sua aplicação sobre o olho). A principal desvantagem é a distância entre os elementos, ou seja, com pequenos aumentos nas distâncias entre os elementos do campo magnético, há uma diminuição muito grande da força transmitida ${ }^{(1)}$.

\section{Nistagmo}

Termo utilizado para descrever movimentos oculares oscilatórios, rítmicos e repetitivos. 
Classifica-se o nistagmo de acordo com a manifestação clínica. O pendular mostra velocidade aproximadamente igual em ambos os sentidos e o sacádico caracteriza-se por apresentar duas fases com velocidades distintas, isto é, com o movimento em um sentido reconhecidamente mais rápido que o no sentido inverso.

O movimento lento é devido à ação do músculo hiperfuncionante e o rápido é o corretivo ${ }^{(2)}$.

\subsection{Condutas terapêuticas nos nistagmos}

A terapêutica para o nistagmo tem se mostrado limitada. $\mathrm{O}$ tratamento óptico mais difundido é o uso de prismas, que têm duas finalidades: corrigir o torcicolo, resultante de uma posição de bloqueio, distinta da posição primária (bases dos prismas colocadas para o mesmo lado) ou estimular a convergência (bases colocadas temporalmente) $)^{(2-3)}$.

O tratamento cirúrgico do nistagmo objetiva a melhora da acuidade visual e a eliminação do torcicolo. Os casos de nistagmos mais favoráveis são aqueles nos quais há posição de bloqueio total ou parcial ${ }^{(3)}$.

\subsection{Introdução de forças pelo uso de campos magnéticos}

O uso de forças de campo magnético para a correção de defeitos dinâmicos do sistema oculomotor, sejam eles por falta de movimentos (paralisias neuromusculares, miopatias, agenesias ou desinserções musculares, etc.) ou para estabilizar os inadequados (nistagmos, lentas modificações posicionais após cirurgias, etc.), tem sido estudado, mostrando uma série de vantagens: forças magnéticas agem sem contato material direto entre o olho e a fonte bem como a condição de inocuidade aos tecidos biológicos ${ }^{(4)}$.

\subsection{Elementos geradores de forças (ímãs)}

Apesar de uma disponibilidade grande de ímãs no mercado, são os compostos de uma liga de neodímio, ferro e boro (Ne-Fe-B) os que, presentemente, oferecem as maiores concentrações de fluxo magnético gerado por volume de material (possibilitando as melhores miniaturizações), condição muito necessária quando são pretendidos artefatos de tamanho reduzido, que viabilizem a construção de um circuito magnético adequado aos olhos.

Para a fixação do ímã na parede orbitária lateral, o ímã deve ser recoberto com uma película protetora (silicone ou ouro) para isolá-lo de tecidos e fluidos orgânicos, já que os ímãs mais adequados para a geração de força (ímã de $\mathrm{Ne}-\mathrm{Fe}-\mathrm{B}$ ) possuem, em sua composição, elementos que podem causar efeitos tóxicos.

Os boratos são utilizados em sabonetes, detergentes, fertilizantes, preservação da madeira, fabricação de fungicidas e na preparação de tintas, pois retardam a propagação do fogo. A ingestão de ácido bórico ou absorção após a aplicação local podem levar a náuseas, vômitos, diarréia, anemia, convulsões e erupções cutâneas caracterizadas por eritema intenso, descamação e esfoliação e alopecia ${ }^{(5)}$. Os efeitos biológicos do neodímio são poucos conhecidos.

\subsection{Ouro como película protetora do ímã}

O ouro é muito utilizado na Odontologia, especialmente na sua forma pura. É o mais nobre de todos os materiais empregados, raramente sofrendo corrosão. Na cavidade oral, ele é inativo quimicamente e não é afetado pelo ar, calor, umidade, e nem pela maioria dos solventes. Seus possíveis efeitos nocivos sobre a polpa têm sido discutidos e, quando condensado adequadamente, produz resposta inflamatória pulpar mínima em uma estrutura dentária sadia ${ }^{(6)}$.

Este trabalho experimental visou contribuir para a concretização de aplicações práticas do uso de campos magnéticos em Oftalmologia, estudando-se aspectos da implantação de ímãs à órbita.

\section{OBJETIVO}

Avaliação histológica do tecido retirado per-implante, em órbitas de coelhas.

\section{MÉTODOS}

\section{Materiais}

1) Ímãs de terra rara (neodímio, ferro e boro), medindo $5 \mathrm{~mm}$ de diâmetro por 2,5 $\mathrm{mm}$ de altura, foram envolvidos por duas chapas de ouro maciças, uma de 10 micrômetros, envolvendo a parte anterior do ímã, e outra medindo 35 micrômetros, desde a base do ímã até o ápice, encontrando, então, a chapa de 10 micrômetros da face anterior. $\mathrm{O}$ implante (complexo formado pelo ímã e as duas chapas em ouro) mediu 13,0 mm horizontalmente e 3,0 $\mathrm{mm}$ verticalmente, sendo elaborado artesanalmente em um serviço privado e sempre pela mesma pessoa (Figura 1).

2) Coelhas Nova Zelândia de peso variando de 1,8 a $2,2 \mathrm{~kg}$, de 3 a 5 meses de vida, em número de 54, fornecidas pelo biotério da Faculdade de Medicina de Ribeirão Preto, da USP, divididas em lotes (num total de 18), contendo 3 coelhas cada lote, para estudos após uma, três e seis semanas da implantação (Aprovado pelo Comitê de Ética em Pesquisa em Animais).

3) Fios de polipropileno 5.0, com agulha redonda de $1,5 \mathrm{~cm}$.

4) Fios monofilamentares 5.0, com agulha cortante de $1,5 \mathrm{~cm}$ (nylon 5.0).

5) Cola do tipo cianoacrilato, em forma de gel - Superbon$\operatorname{der}^{\circledR}$. Loctite.

6) Parafusos de platina, de $5 \mathrm{~mm}$ de comprimento por $0,9 \mathrm{~mm}$ de diâmetro, auto-rosqueantes.

\section{Métodos}

\subsection{Fixação do implante}

O ímã, recoberto pelo ouro foi fixado na borda orbitária inferior das coelhas, por meio de fio de polipropileno 5.0 no periósteo ou por cola do tipo cianoacrilato, em forma de gel, ou por parafuso de platina auto-rosqueante. 


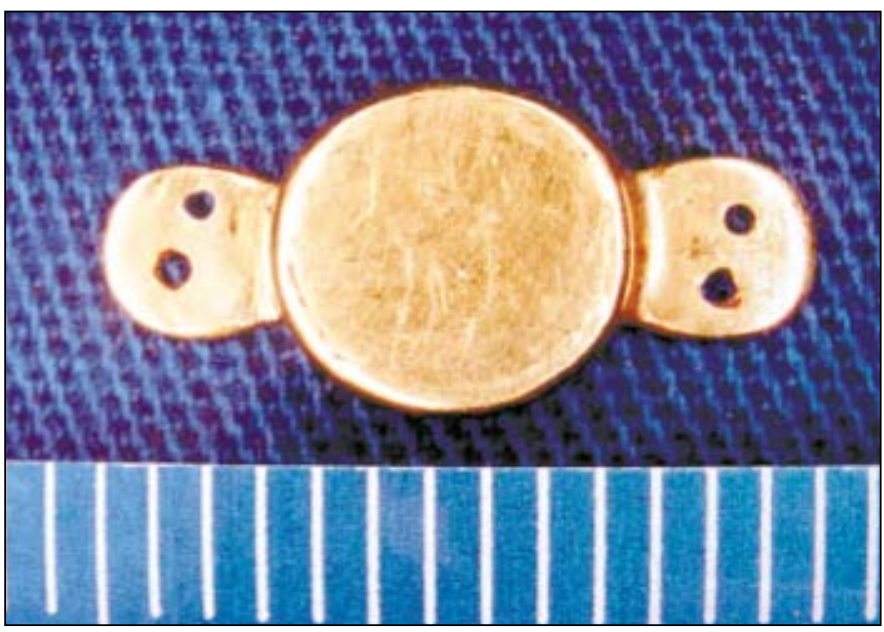

Figura 1 - Modelo utilizado e sua medida horizontal $(13 \mathrm{~mm})$

\subsection{Sorteio}

Sorteio da ordem dos tipos e dos grupos de pesquisa para cada lote (1-18). O grupo controle, para cada lote, foi constituído da órbita contralateral de cada coelha. Estas foram numeradas de 1 a 54, ou seja, o lote número 1, contendo três coelhas, contou com as coelhas $1,2,3$, e assim por diante, respeitandose a ordem de chegada. Os animais foram retirados da mesma gaiola no biotério, levados no dia do implante e colocados em gaiolas, com três coelhas (correspondendo a um lote), cada um permanecendo juntas até a data da retirada do implante.

Para a classificação, as coelhas foram divididas em três grupos de pesquisa de 18 animais cada um, designados como C, $\mathrm{P}$ e F (para cola, parafuso e fio, respectivamente). Cada um desses três grupos foi dividido em subgrupos com seis coelhas, dependendo do tipo de fixação do implante e do tempo de permanência, ou seja, C-1 para cola e uma semana, C-3 para cola e três semanas e C-6 para cola e seis semanas; $\mathrm{P}-1$ para parafuso e uma semana, P-3 para parafuso e três semanas e P-6 para parafuso e seis semanas; F-1 para fio e uma semana, F-3 para fio e três semanas e F-6 para fio e seis semanas. As órbitas foram divididas em: tratadas com implante (ímã recoberto pelo ouro) e tratadas sem implante ou seja, quando foi apenas a abertura por planos, mas sem fixação do implante (controle).

\subsection{Procedimento cirúrgico}

Cada coelha foi pesada e, 10 minutos após medicação préanestésica contendo Ketamina $2 \mathrm{ml}$ via intramuscular (IM) e Xilazina $1 \mathrm{ml}$ (IM), administraram-se $10 \mathrm{mg} / \mathrm{kg}$ de Tiopental via endovenosa (EV) para complementação anestésica; quando necessário, foi feito reforço por $10 \mathrm{mg} / \mathrm{kg}$ de Tiopental (EV).

Após tricotomia e anti-sepsia da pele, fez-se a abertura da borda orbitária inferior, com incisões de $2,5 \mathrm{~cm}$, dissecção por planos até o periósteo, que foi descolado para a fixação - ou não (controle) - do implante: no próprio periósteo, no caso de fixação pelo fio; ou no rebordo orbitário, no caso de uso de cola ou parafuso.
Após a fixação do implante, ou não (órbita tratada sem implante), aproximou-se o tecido subcutâneo com o fio de polipropileno por sutura contínua e a pele com fio monofilamentar inabsorvível, também com chuleio simples. A cada duas órbitas, trocou-se a lâmina do bisturi para minimizar o traumatismo e, a cada coelha, trocaram-se as luvas cirúrgicas.

\subsection{Retirada do implante}

$\mathrm{Na}$ data da retirada do implante, as coelhas foram sacrificadas com Tiopental (EV), após o que se realizou a abertura dos tecidos, por planos, até a localização do implante e do periósteo, na órbita contralateral (Figura 2).

\subsection{Exame histológico}

Os tecidos que envolviam o implante, bem como os da órbita contralateral (tratada sem implante), foram retirados cuidadosamente, colocados em formalina, fixados em parafina e corados pela técnica de Hematoxilina-Eosina e rotulados como da órbita direita (D), e esquerda (E).

$\mathrm{O}$ estudo qualitativo e quantitativo nos diferentes tempos de implantação dos implantes foi realizado por dois patologistas, que desconheciam os grupos dos quais as coelhas provinham.

A classificação qualitativa dos achados histológicos considerou, na fase aguda, a presença (1) ou ausência (0) de congestão vascular e infiltrado neutrofílico, e, na crônica, a presença (1) ou ausência (0) de infiltrado mononuclear (linfócitos e histiócitos), infiltrado granulomatoso (gigantócitos) e fibrose.

A classificação quantitativa do processo inflamatório, na área de fibrose, considerou: ausência (a), quando não foram encontrados neutrófilos na fase aguda ou células mononucleares na fase crônica; presença discreta (+) quando até $30 \%$ de neutrófilos na fase aguda ou de células mononucleares na fase crônica; presença moderada (++), de 31 a $60 \%$ de neutrófilos na fase aguda ou de células mononucleares na fase crônica; presença acentuada (+++), quando mais de $61 \%$ de neutrófilos na fase aguda ou células mononucleares na fase crônica.

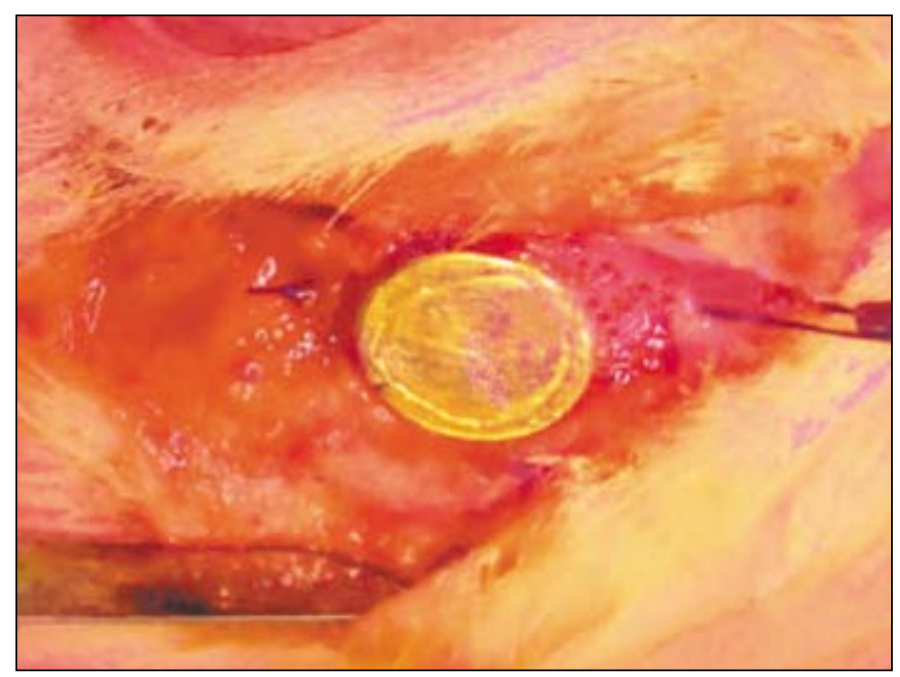

Figura 2 - Localização do implante 
Diante da presença concomitante de neutrófilos e células mononucleares (linfócitos e histiócitos), consideraram-se os predominantes. Os granulomas foram considerados ausentes (a), com presença discreta (+), quando em número de 1 a 5 ; presença moderada $(++)$, quando em número de 6 a 10 , e acentuada (+++), quando em número acima de 10 , na área total da lâmina examinada. A fibrose foi classificada como ausente (a), quando nenhuma fibrose estava presente na área total examinada; com presença discreta (+), quando até $30 \%$ de fibrose estava presente na área total examinada; com presença moderada (++), quando 31 a $60 \%$ de fibrose estava presente na área total examinada; e com presença acentuada $(+++)$, quando mais de $61 \%$ da área total examinada apresentava fibrose.

\section{Análise estatística}

Foram realizadas análises descritivas quando nenhum teste estatístico de significância era adequado ou a simples composição de valores era insuficiente para a tomada de conclusões. Aplicou-se o programa Systat ${ }^{\circledR} 7.00$ aos estudos estatísticos. Para a comparação entre as órbitas tratadas com e sem implante, dentro de cada subgrupo, foi utilizado o teste não paramétrico de Wilcoxon, para dados pareados. Para o estudo entre os subgrupos de um mesmo grupo, nos seus respectivos períodos pós-operatórios, e para o estudo de diferentes subgrupos em um mesmo período, foi aplicado o teste não paramétrico de Mann-Whitney. Tais análises consideraram os seguintes aspectos:

- microscopicamente: infiltrado neutrofílico, congestão vascular, infiltrado mononuclear (linfócitos e histiócitos), infiltrado granulomatoso e fibrose.

Em todos os testes, foram apresentados os valores de "p". Adotou-se o nível de significância de 5\% $(0,05)$.

\section{RESULTADOS}

Os resultados são descritos nas tabelas 1, 2, 3 e 4 respectivamente.

Verificou-se presença de neutrófilos em 34 e ausência em 20 das órbitas tratadas sem implante. Já nas órbitas tratadas com implante, a congestão vascular deu-se em 47 e, a ausência, em 7 (Tabela 2).

A presença de neutrófilos deu-se em 26 olhos (e ausência em 28) das órbitas sem implante e em 34 (ausência em 20) das órbitas com implante (Tabela 2).

Considerando o processo inflamatório crônico (linfócitos e histiócitos), nas órbitas tratadas com implante, observou-se presença em 47 e ausência em sete órbitas (Tabela 2). Já nas órbitas tratadas sem implante, 32 apresentaram células que caracterizavam o processo inflamatório crônico, que e em 22 estava ausente (Tabela 2).

A reação granulomatosa fez-se presente em 35 e ausente em 19 das órbitas tratadas com implante e, respectivamente, em 26 e 28 nas órbitas sem implante (Tabela 2).

A fibrose esteve presente em 51 e ausente em três órbitas tratadas com implante; e, nas órbitas sem implante, 40 apresentaram fibrose e 14 não (Tabela 2).

Em todas as órbitas tratadas com ou sem implante, observou-se predomínio das células mononucleares (linfócitos e histiócitos), ocorrendo predomínio acentuado em 39 órbitas, moderado em seis órbitas e leve em duas (Tabela 4). Assim, também houve predominância do processo inflamatório crônico nas órbitas tratadas sem implante e, em 31 órbitas, notou-se predomínio acentuado de células mononucleares e, em apenas uma, moderado (Tabela 4).

\section{DISCUSSÃO}

\section{Estudo histopatológico}

Sempre que um corpo estranho entra em contato com um tecido vivo, seja material de sutura ou qualquer outra substância, provoca no organismo uma resposta celular imediata. $\mathrm{Na}$ primeira etapa em geral, nos primeiros dias, há predomínio de neutrófilos, caracterizando a fase aguda do processo inflamatório, os quais são substituídos por células mononucleares, constituídas por linfócitos e histiócitos, iniciando-se, assim, a fase crônica do processo inflamatório.

A última etapa é a do processo de cicatrização, no qual o tecido lesado é substituído por tecido conjuntivo vascularizado, condição capaz de ocorrer independentemente de a origem da lesão ser traumática ou necrótica, acontecendo o acúmulo continuado de colágeno, produzido pelos fibroblastos em proliferação, com progressiva diminuição do infiltrado linfocitário e dos vasos sanguíneos proliferados ${ }^{(7)}$.

\begin{tabular}{|c|c|c|c|c|c|c|c|c|c|c|c|}
\hline Fases & Sinais & $\begin{array}{r}\text { Grupo } \\
\text { Sub-grupos }\end{array}$ & \multicolumn{3}{|c|}{ C (Cola) } & \multicolumn{3}{|c|}{ P (Parafuso) } & \multicolumn{3}{|c|}{ F (Fio) } \\
\hline \multirow[t]{2}{*}{ Aguda } & Congestão vascular & & $5 / 6$ & $5 / 4$ & $-/ 4$ & $5 / 5$ & $5 / 6$ & $4 / 4$ & $6 / 6$ & $3 / 6$ & $1 / 6$ \\
\hline & Infiltrado neutrofílico & & $5 / 6$ & $4 / 3$ & $-/ 2$ & $4 / 5$ & $2 / 5$ & $3 / 2$ & $5 / 4$ & $2 / 3$ & $1 / 4$ \\
\hline Crônica & Infiltrado mononuclear & & $5 / 6$ & $5 / 4$ & $-/ 4$ & $5 / 5$ & $4 / 6$ & $3 / 4$ & $6 / 6$ & $3 / 6$ & $1 / 6$ \\
\hline
\end{tabular}


Tabela 2. Número de órbitas com presença (p) ou ausência (a) de sinais histopatológicos nas fases inflamatórias aguda e crônica dos procedimentos cirúrgicos, nos grupos $C$ (cola) ou $\mathrm{P}$ (parafuso) ou $\mathrm{F}$ (fio), tratadas com implante (denominador) e sem ele (numerador, grupo controle)

\begin{tabular}{|c|c|c|c|c|c|c|c|c|c|c|}
\hline \multirow[t]{2}{*}{ Fases } & \multirow[t]{2}{*}{ Sinais } & \multirow[t]{2}{*}{ Grupo } & \multicolumn{2}{|c|}{ C (Cola) } & \multicolumn{2}{|c|}{ P (Parafuso) } & \multicolumn{2}{|c|}{ F (Fio) } & \multicolumn{2}{|c|}{ Total } \\
\hline & & & $\mathbf{p}$ & $\mathbf{a}$ & $p$ & $\mathbf{a}$ & $\mathbf{p}$ & $\mathbf{a}$ & $p$ & a \\
\hline \multirow[t]{2}{*}{ Aguda } & Congestão vascular & & $10 / 14$ & $8 / 4$ & $14 / 15$ & $4 / 3$ & $10 / 18$ & $8 /-$ & $34 / 47$ & $20 / 7$ \\
\hline & Infiltrado neutrofílico & & $9 / 11$ & $9 / 7$ & $9 / 12$ & $9 / 6$ & $8 / 11$ & $10 / 7$ & $26 / 34$ & $28 / 20$ \\
\hline \multirow[t]{3}{*}{ Crônica } & Infiltrado mononuclear & & $10 / 14$ & $8 / 4$ & $12 / 15$ & $6 / 3$ & $10 / 18$ & 8/- & $32 / 47$ & $22 / 7$ \\
\hline & Infiltrado granulomatoso & & $8 / 14$ & $10 / 4$ & $9 / 8$ & $9 / 10$ & $9 / 13$ & $9 / 5$ & $26 / 35$ & $28 / 19$ \\
\hline & Fibrose & & $12 / 16$ & $6 / 2$ & $14 / 17$ & $4 / 1$ & $14 / 18$ & $4 /-$ & $40 / 51$ & $14 / 3$ \\
\hline
\end{tabular}

\begin{tabular}{|c|c|c|c|c|c|c|c|c|c|c|c|}
\hline \multirow[t]{2}{*}{ Inflamação } & \multirow{2}{*}{\multicolumn{2}{|c|}{$\begin{array}{r}\text { Grupo } \\
\text { Sub-grupos }\end{array}$}} & \multicolumn{3}{|c|}{ C (Cola) } & \multicolumn{3}{|c|}{ P (Parafuso) } & \multicolumn{3}{|c|}{ F (Fio) } \\
\hline & & & C-1 & C-3 & C-6 & $P-1$ & P-3 & P-6 & F-1 & F-3 & F-6 \\
\hline Ausente & - & & $1 /-$ & $1 / 2$ & $6 / 2$ & $1 / 1$ & $2 /-$ & $3 / 2$ & - & $3 /-$ & $5 /-$ \\
\hline $\begin{array}{l}\text { Presente } \\
\text { Neutrófilos }\end{array}$ & $\begin{array}{l}+ \\
++ \\
+++\end{array}$ & & & & & & & & & & \\
\hline Mononucleares & $\begin{array}{l}+ \\
++ \\
+++\end{array}$ & & $\begin{array}{l}-/ 2 \\
5 / 4\end{array}$ & $5 / 4$ & $\begin{array}{l}-/ 1 \\
-/ 3\end{array}$ & $5 / 5$ & $\begin{array}{l}-/ 1 \\
4 / 5\end{array}$ & $3 / 4$ & $\begin{array}{l}-/ 2 \\
6 / 4\end{array}$ & $\begin{array}{l}-/ 1 \\
1 /- \\
2 / 5\end{array}$ & $\begin{array}{l}-/ 1 \\
1 / 5\end{array}$ \\
\hline
\end{tabular}

\begin{tabular}{|c|c|c|c|c|c|c|}
\hline $\begin{array}{l}\text { Inflamação } \\
\text { Mononucleares }\end{array}$ & & Grupo & C (Cola) & P (Parafuso) & F (Fio) & Total \\
\hline Com implante & $\begin{array}{l}+ \\
++ \\
+++\end{array}$ & & $\begin{array}{r}1 \\
2 \\
11\end{array}$ & $\begin{array}{r}- \\
1 \\
14\end{array}$ & $\begin{array}{r}1 \\
3 \\
14\end{array}$ & $\begin{array}{r}2 \\
6 \\
39\end{array}$ \\
\hline Sem implante & $\begin{array}{l}+ \\
++ \\
+++\end{array}$ & & $\begin{array}{c}- \\
- \\
10\end{array}$ & $\begin{array}{c}- \\
- \\
12\end{array}$ & $\begin{array}{l}- \\
1 \\
9\end{array}$ & $\begin{array}{r}- \\
1 \\
31\end{array}$ \\
\hline
\end{tabular}

A presença de eosinófilos no infiltrado mononuclear pode representar reação tissular de hipersensibilidade ou infecção parasitária local.

Comparando-se as órbitas tratadas com implante, nos seus respectivos tempos, nos grupos $\mathrm{C}, \mathrm{P}$ e F, quanto ao infiltrado neutrofílico, observou-se somente nível de significância entre 1 e 6 semanas $(p=0,02)$, no grupo $C$ (cola). Nesse caso, os neutrófilos estão presentes em todas as órbitas, na primeira semana, e ausentes em quatro das seis órbitas, na sexta semana. Não houve diferença estatística para a congestão vascular e infiltrado mononuclear. Para o infiltrado granulomatoso, a comparação entre subgrupos P-1 x P-6 e entre P-3 x P-6 apresentou diferença estatisticamente significante com $\mathrm{p}=0,02$ nos dois casos. Notou-se que, nos dois casos (P-1 x P-6 e P-3 x P-6), quatro das seis órbitas na primeira e na terceira semana, os granulomas faziam-se presentes e, na sexta semana, eles estavam ausentes em todas as órbitas. Quanto à fibrose, não houve diferença estatisticamente significante na comparação entre os tempos de cada grupo.

\section{Estudo histopatológico na primeira semana do período pós-operatório}

O estudo estatístico não revelou diferença estatisticamente significante nas órbitas tratadas com implante e sem implante, nos subgrupos C-1, P-1 e F-1, quanto aos neutrófilos, congestão vascular, infiltrado mononuclear, infiltrado granulomatoso e fibrose, bem como na comparação entre as órbitas tratadas com implante (C-1 e P-1; C-1 e F-1; P-1 e F-1). Nos subgrupos $\mathrm{C}-1, \mathrm{P}-1, \mathrm{~F}-1$ e nas órbitas tratadas com e sem implante, observou-se o predomínio da reação inflamatória crônica acentuada (Tabela 3 e Figura 3). No subgrupo C-1, uma coelha, com implante, apresentou eosinofilia moderada, enquanto outra apresentou neutrofilia leve, com esteatonecrose, possivelmente em conseqüência do manuseio da gordura. Numa terceira (subgrupo C-1), também tratada com implante, notou-se acentuada presença de (18) granulomas.

No subgrupo P-1, uma coelha, com implante, o infiltrado neutrofílico leve, com esteatonecrose, fez-se presente. Em 


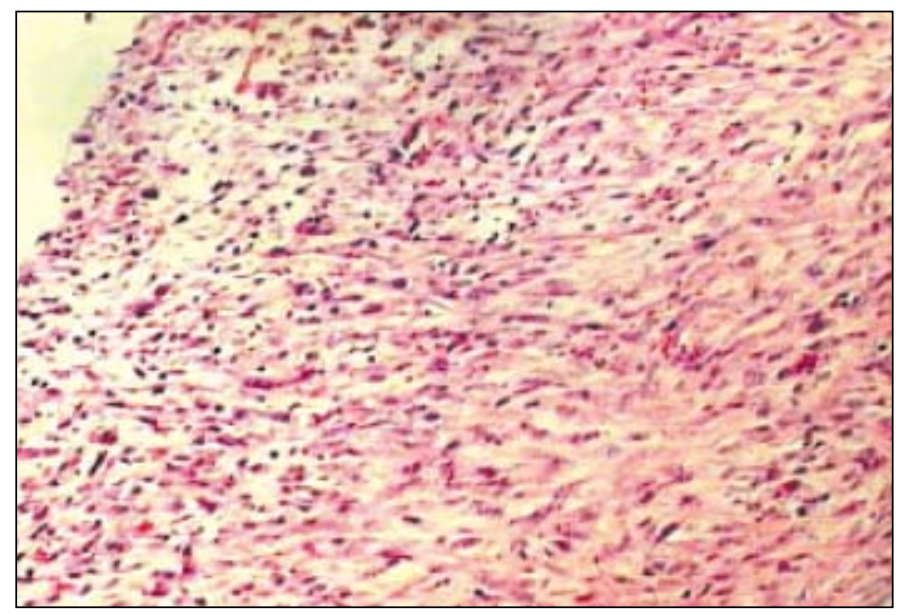

Figura 3 - Corte histológico apresentando infiltrados linfocitário e histiocitário acentuados na primeira semana do período pós-operatório, com o uso da cola. HE x 100

outra, sem implante, houve reação granulomatosa acentuada. Já no subgrupo F-1, em uma coelha, sem implante, notou-se presença acentuada de granuloma.

\section{Estudo histopatológico na terceira semana do período pós-operatório}

O estudo estatístico não revelou diferença estatisticamente significante entre as órbitas tratadas com implante e tratadas sem implante, nos subgrupos C-3, P-3 e F-3, quanto aos neutrófilos, congestão vascular, infiltrado mononuclear, infiltrado granulomatoso e fibrose, bem como na comparação entre as órbitas tratadas com implante (C-3 e P-3; C-3 e F-3; P-3 e F-3). Em todos os subgrupos (C-3, P-3, F-3) e em órbitas tratadas com e sem implante, houve predominância do processo inflamatório crônico acentuado (Tabela 3). Em uma coelha, do subgrupo F-3, com implante, notou-se presença moderada de eosinófilos e necrose degenerativa, possivelmente pela própria presença do fio para fixação e manipulação da gordura. Em outra do mesmo subgrupo, tratada sem implante, observou-se presença de eosinofilia moderada.

\section{Estudo histopatológico na sexta semana do período pós-operatório}

O estudo estatístico não revelou diferença estatisticamente significante nas órbitas tratadas com implante e tratadas sem implante, nos subgrupos C-6, P-6 e F-6, quanto aos neutrófilos. Já na congestão vascular, houve diferença estatisticamente significante entre os subgrupos C-6 e F-6, com p=0,05 e 0,03 respectivamente. No subgrupo C-6, observou-se presença de congestão vascular em quatro das seis órbitas e, no controle, ausência em todas as órbitas, e no subgrupo F-6, observou-se presença em todas e ausência em cinco das seis órbitas de congestão vascular. O infiltrado mononuclear mostrou ausência de diferença estatisticamente significante entre os subgrupos C-6 (presença e ausência em quatro e em seis órbitas, respectivamente) ( $\mathrm{p}=0,05)$ e F-6 (presença e ausência em seis e em cinco das seis órbitas respectivamente) $(\mathrm{p}=0,03)$. $\mathrm{O}$ infiltrado granulomatoso apresentou diferença estatisticamente significante entre os subgrupos C-6, com p=0,05 (presença e ausência em quatro e em seis órbitas, respectivamente) e a fibrose, com $\mathrm{p}=0,05$, no subgrupo F-6 (presença e ausência em seis e em quatro das seis órbitas, respectivamente). Considerando-se o infiltrado granulomatoso e na comparação entre as órbitas tratadas com implante, no mesmo período e em diferentes grupos, nos subgrupos C-6 (presença em quatro órbitas) x P-6 (ausência nas seis órbitas) entre P-6 (ausência nas seis órbitas) x F-6 (presença nas quatro das seis órbitas), observou-se $\mathrm{p}=0,02$ nos dois casos.

Em todos os subgrupos (C-6, P-6, F-6) e nas órbitas tratadas com e sem implante, observou-se o predomínio da reação inflamatória crônica e o predomínio da ausência de reação respectivamente (Tabela 3). É possível que a perduração do processo inflamatório crônico, nas órbitas tratadas com implante, deva-se à presença dele; e que o predomínio da ausência, nas órbitas tratadas sem implante, pela sua ausência. No subgrupo C-6, uma coelha, com implante, apresentou eosinofilia e reação granulomatosa acentuada (onze granulomas) (Figura 4). Já em outra, no mesmo subgrupo, observou-se acentuada reação granulomatosa (22) e, além disso, o implante apresentou-se danificado na sua parte superior; é possível que a presença acentuada de granuloma se deva, em parte, à ruptura do implante, com exposição, aos fluidos orgânicos, dos componentes do ímã.

Em uma coelha do subgrupo F-6, notou-se presença moderada de eosinófilos e acentuada de granulomas (40). É possível que isto se deva, em parte, à presença do tipo de fixação (fio inabsorvível) e em parte pela alteração na integridade do implante, com exposição dos produtos do ímã aos fluídos orgânicos (Figura 5).

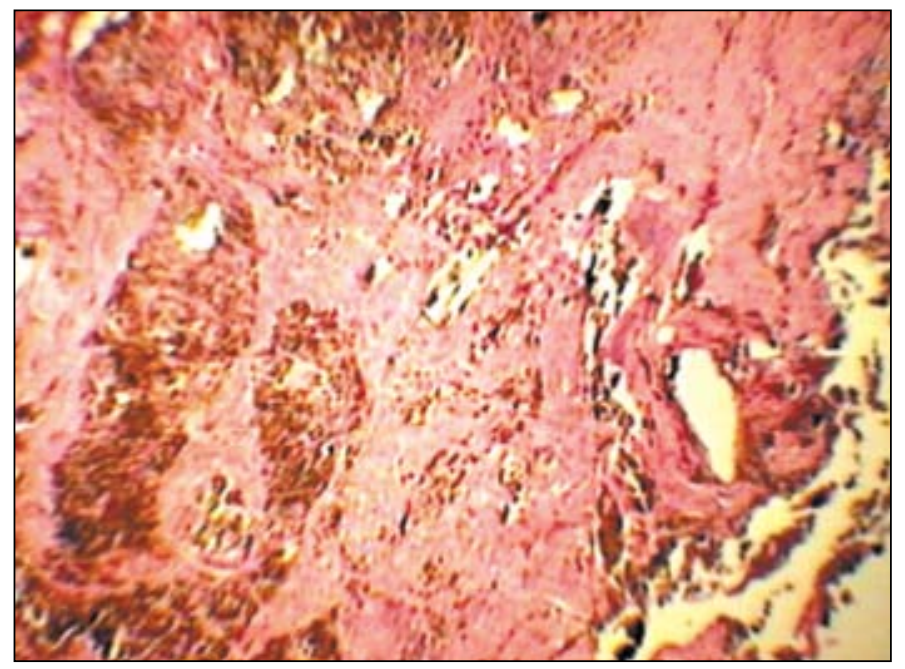

Figura 4 - Corte histológico apresentando infiltrados granulomatoso, linfocitário e histiocitário acentuados na sexta semana do período pós-operatório, com o uso da cola. Implante danificado na parte superior. HE x 400 


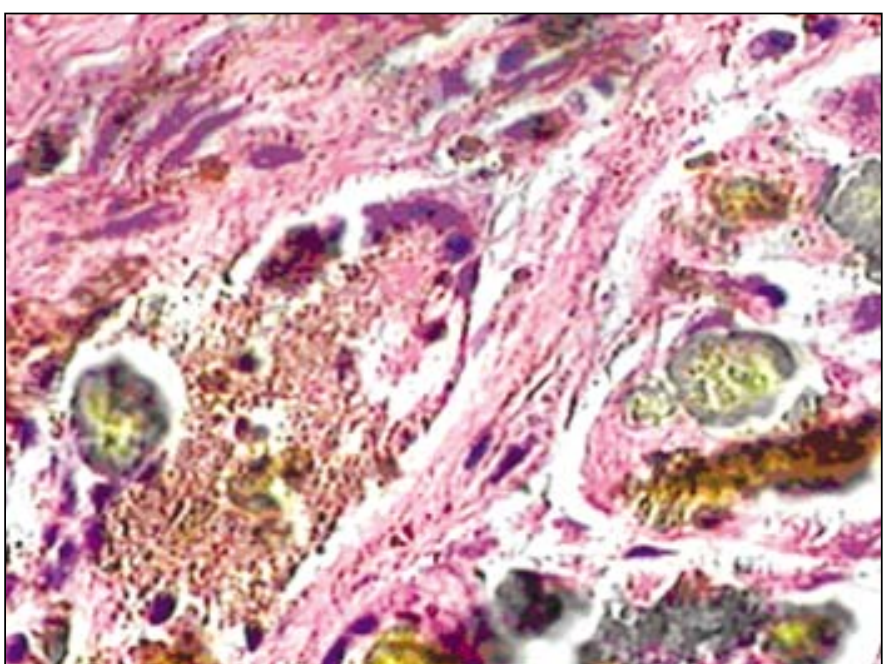

Figura 5 - Corte histológico apresentando infiltrados granulomatoso, linfocitário e histiocitário acentuados na sexta semana do período pósoperatório, com o uso do fio. Implante danificado na parte superior. HE X 400

\section{CONCLUSÃO}

O exame histopatológico demonstrou, na maior parte das órbitas com e sem implante, presença de reação inflamatória aguda e crônica até a sexta semana pós-operatória, com predomínio de processo inflamatório crônico e fibrótico cicatricial, sem demonstrar, na maior parte dos casos, diferenças estatisticamente significante entre os grupos experimental e controle.

\section{ABSTRACT}

Purpose: To evaluate microscopically the signs of inflammatory reaction due to the fixation of an orbitary implant (magnet, covered by gold). Methods: An experimental study was perfor- med in 54 adult female rabbits, divided into 3 groups of eighteen with 3 subgroups of 6 ; an evaluation at 1, 3 and 6 postoperative weeks was performed. An implant (magnet, covered by gold) was fixed in the inferior orbital rim using biologic glue, screw or unabsorbable suture (Mersilene 5.0 ${ }^{\circledR}$ ). The opposite orbits (without implants) represented the control group. Results: Microscopic signs of inflammatory reaction due to orbitary fixation of the implant were observed with the use of the three methods (biologic glue, screw or unabsorbable suture) (Mersilene $5.0^{\circledR}$ ), until six weeks of the postoperatory period. Conclusions: Histopathological signs of inflammatory reaction to the implant and to its orbital fixation were observed up to the sixth week, with cyanoacrylate, screw, or unabsorbable suture (Mersilene $5.0^{\circledR}$ ), with prevalence of the chronic inflammatory process and cicatricial fibrosis, without statistically significant difference in most of the cases.

Keywords: Orbital implants/adverse effects; Magnetics/therapeutic use; Gold/adverse effects; Nystagmus pathologic/surgery; Rabbits; Comparative study

\section{REFERÊNCIAS}

1. Bicas HEA. Gerações de rotações binoculares combinadas em casos de perdas de ação muscular: mecanismos para conjugações rotacionais. Arq Bras Oftalmol. 1996;59(2):119-28.

2. Carvalho LEMR. Nistagmo. Arq Bras Oftalmol. 1998;61(4):473-5.

3. Bicas HEA. Ajustamentos posicionais oculares e estabilizações do equilíbrio oculomotor sem impedir rotações. Arq Bras Oftalmol. 1998;61(3):294-304.

4. Bicas HEA. Cirurgia dos nistagmos [resumo]. In: $14^{\circ}$ Congresso do Conselho Latino-Americano de Estrabismo; 2000. Anais. São Paulo; 2000. p.109-16.

5. Louria DB. Intoxicação por oligoelementos. In: Cecil RL. Tratado de medicina interna. 19a ed. Rio de Janeiro: Guanabara Koogan; 1993. p.2416-25.

6. Kenneth JA. Restaurações diretas em ouro e sua manipulação. In: Kenneth JA. Phillips: Materiais dentários. 10a ed. Rio de Janeiro: Guanabara Koogan; 1998. p.241-7.

7. Moreira ATR, Torres LFB, Scarpi MJ, Moreira Junior CA, Miranda SP, Matsumoto LH. Uso do adesivo biológico de fibrina para reinserção de músculos retos superiores em coelhos: I - estudo clínico. Rev Bras Oftalmol. 1998;57(7):501-12.
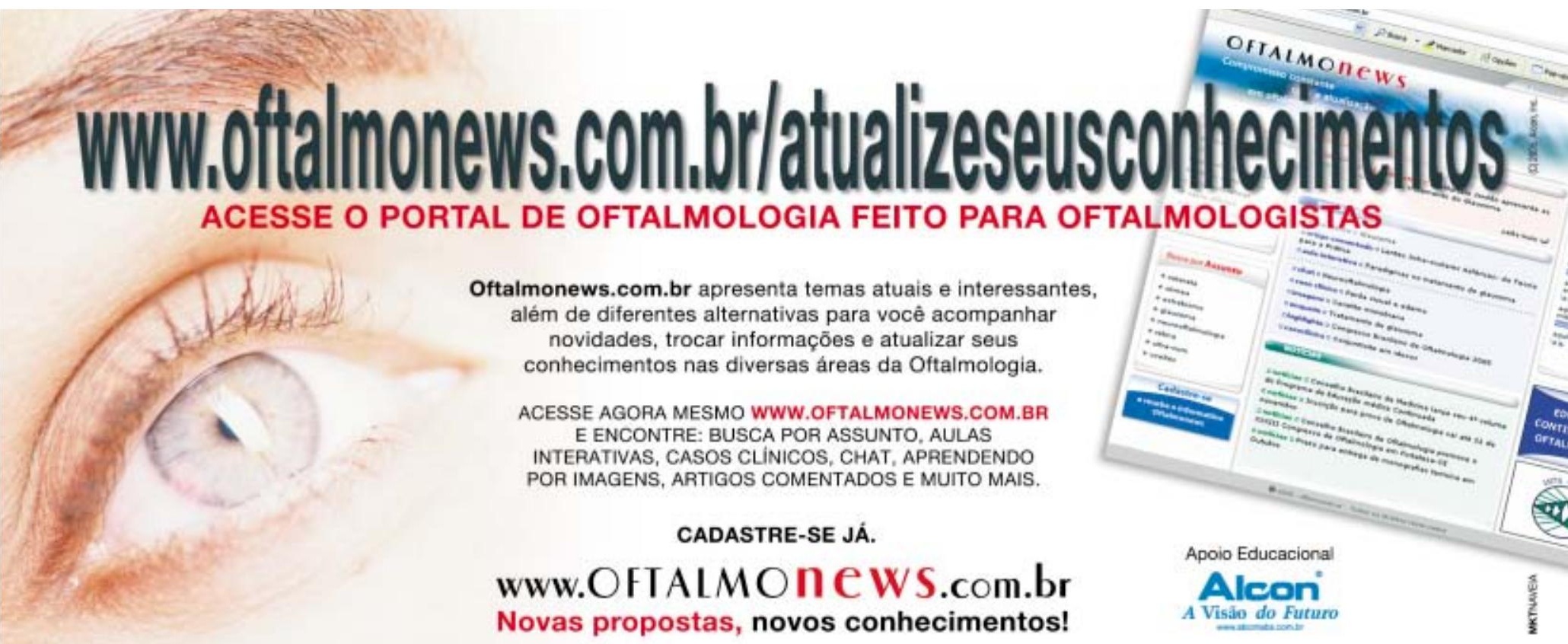

\section{-}

